\title{
Patterns of scuba diver behaviour to assess environmental impact on marine benthic communities: a suitable tool for management of recreational diving on Benidorm island (Western Mediterranean sea).
}

Jimenez-Gutiérrez, S.(1), Martín González, G.(2) y Tena Medialdea. J.(2)

(1) Institut d'Ecologia Litoral, El Campello (Alicante)

(2) Instituto de Investigación en Medio Ambiente y Ciencia Marina (IMEDMAR)

Universidad Católica de Valencia, Valencia

Scuba diving is one of the tourist activities with the greatest growth over the last few years. Nevertheless, few studies have analyzed the SCUBA divers' behaviour in the Mediterranean Sea and none of them involved marine unprotected areas. Generally speaking the damage done by individuals is quite low, but the, accumulative effects of these disturbances can cause significant localised destruction of benthic marine organisms. The present study was carried out on a diving site called La Llosa, on Benidorm Island (Alicante: Western Mediterranean Sea) with more than 7,000 dives per year. The depth at the most superficial part is $6 \mathrm{~m}$ and its south face descends abruptly reaching $30 \mathrm{~m}$ in depth. Samples were randomly collected during the high diving season (June-October). The data were collected during the diving high season (June-October) in the year 2005. Divers were not aware of this surveillance so as not to interfere with their normal patterns of behaviour. The noted actions were divided into two groups: a) Number of contacts with different parts of the body (hands, knees) or equipment (fins, octopus, console tank air), but without taking into account the derived consequences on the sea bottom, and b) Resulting actions (turbidness, the taking or alteration of benthic organisms).Two hundred and seventeen (217) divers were monitored randomly. Each subject was observed underwater for 10 minutes The diver's actions as well as how often each diver made direct physical contact with the substratum were noted.

The results showed that $95 \%$ of divers came into physical contact with benthic substrata during the 10-min observation period. When the contacts made with parts of the diver's equipment or with the parts of their body were analyzed, we observed that there existed differences regarding the most studied diving sites, such as coral reefs. Fin contact rates were significantly different depending on the diving certification level (Man-Whitney test, $p<0.003$ ) detecting the greatest number of contacts within higher diving certification levels (Bonferroni correction). Divers using an underwater light device came intocontact with the substratum significantly more frequently than non-light users $(2, p<0.022)$. However, contact rate did not show significant variance across divers using a camera and those who did not $(p<0.366)$. No difference was found between contact rates of divers who were given a briefing and those who were not. Environmental briefing before diving had no effect on the divers' hand contact rates ([2, $p<0.194$ ), which shows a low marine environmental sensitivity level of divers. We concluded that the decrease in scuba divers contact rate would take place given an improvement of environmental awareness, specially among professional divers. divers do not have this type of problem when they have to rest their hands somewhere, because their diving sites are characterized by rocky relief bottoms. 